\title{
Maxillary nerve block within the equine pterygopalatine fossa with different volumes: practicability, efficacy and side-effects
}

\author{
Clarissa Michaela Riederl, Carsten Staszyk², Klaus Hopster?', Karsten Feige' and Astrid Bienert-Zeit ${ }^{7}$ \\ 1 Clinic for Horses, University of Veterinary Medicine Hannover, Hannover, Germany \\ 2 Institute of Veterinary Anatomy, Histology, and -Embryology, Justus-Liebig-University of Gießen, Gießen, Germany
}

\begin{abstract}
Summary: The maxillary nerve block within the pterygopalatine fossa is a commonly used technique in equine dental surgery. The objective of the present study was to determine the risks of the maxillary nerve block within the pterygopalatine fossa using two different doses of lidocaine and to evaluate methods for testing adequate analgesia of teeth and gingiva. In a preliminary experiment ten horses were trained to tolerate a mouth gag without sedation. A mechanical and thermal stimulation was applied on the palatal gingiva and the occlusal surface. Thermal as well as mechanical stimulation resulted in a reproducible defense reaction in all horses. The main study was designed as a prospective, randomised, blinded, experimental trial. Ten clinically healthy horses were used in a randomised cross-over design. Horses were sedated with $0.02-0.03 \mathrm{mg} / \mathrm{kg}$ detomidine iv. A maxillary nerve block was performed on one side of the head with the previously described "Extraperiorbital-Fat-Body-Insertion" (EFBI) technique using either $2 \mathrm{ml} / 100 \mathrm{~kg}$ BW lidocaine (group low) or $4 \mathrm{ml} / 100 \mathrm{~kg}$ BW lidocaine (group high). A Schirmer tear test was performed before and after nerve block, on both sides of the head (blocked and non-blocked side). Analgesia of the teeth and the surrounding gingiva was assessed by applying mechanical and thermal stimuli on both sides of the head (blocked and non-blocked side) 10 and 25 minutes after lidocaine injection. Heart rate, respiratory rate, sweating, and change of the pupil size were recorded before and in 5 minute intervals after lidocaine injection for 35 minutes. No side effects were observed in 16 out of 20 experiments. Four horses showed blepharospasm, miosis, swollen palpebrae, superficial corneal ulcer, or uveitis. Symptoms disappeared completely after symptomatic treatment. Lacrimation was reduced after nerve block, even though no statistically significant differences were found for lacrimation rate before and after nerve block. Analgesia of teeth and gingiva was not assessable with thermal and mechanical stimuli in the sedated horse. The used dosage of lidocaine did not influence any of the recorded clinical parameters. Although the pterygopalatine fossa houses delicate anatomical structures, the EFBI-technique appears to be a safe method for blocking the maxillary nerve. It is recommended to apply lubricating ointments to keep the cornea moist and therefore avoid negative side effects on the eye.
\end{abstract}

Keywords: local anaesthesia / analgesia / equine dentistry / maxillary nerve block / lacrimation

Citation: Rieder C. M., Staszyk C., Hopster K., Feige K., Bienert-Zeit A. (2016) Maxillary nerve block within the pterygopalatine fossa of the horse with different volumes: practicability, efficacy and side-effects. Pferdeheilkunde 32, 132-140

Correspondence: Dr. Astrid Bienert-Zeit, Clinic for Horses, University of Veterinary Medicine Hannover, Foundation, Bünteweg 9, 30559 Hannover, Germany; E-Mail: astrid.bienert@tiho-hannover.de

\section{Introduction}

For maxillary cheek teeth extraction, a perineural maxillary nerve block within the pterygopalatine fossa is recommended (Vlaminck and Steenhaut 2001, Fletcher 2004). This nerve block provides excellent dental and paranasal analgesia (Moyer et al. 2011) but bares the risk of iatrogenic neurovascular injuries and ocular damage. Even fatal neurological deficits due to ascending infections are described (Dixon 2006). In order to reduce these risks, the anatomy of the pterygopalatine fossa had been re-examined on cadaveric heads, resulting in a modified technique in which the anaesthetic is injected into the extraperiorbital fat body (Staszyk et al. 2008). However, only few studies have been performed evaluating risks and side effects of this technique under clinical conditions (Nottrott et al. 2014). Questionable is also the volume of local anaesthetic needed for complete nerve coverage. Studies with different volumes are only done on cadaver heads using contrast medium or methylene blue (Staszyk et al. 2008, Bardell et al. 2010).

Techniques to test the correct performance and efficacy of local anaesthesia prior to surgery would be important in equine dentistry. Approved methods which are based on electric and thermal stimulation exist for humans (Hensel and Mann 1956, Naylor 1964, Trowbridge et al. 1980, Ahlquist et al. 1984). Certosimo and Archer (1996) used an electric pulp tester to predict the efficacy of local anaesthesia prior to surgery in man. Several other investigators examined the local effect of anaesthetics for analgesia of the maxillary dental arcade in man by maxillary infiltration (Costa et al. 2005, Evans et al. 2008). Studies in small animals have shown that cold stimulation of teeth evokes nociceptive responses in dental nerves (Wagers and Smith 1960, Funakoshi and Zotterman 1963, Yamada et al. 1968). Further electric tooth-pulp stimulation in halothane-anesthetized cats has been used to test regional block induced analgesia (Gross et al. 2000). Hitherto, no study has been performed to ascertain any methods to prove pain and analgesia in teeth and surrounding gingiva of horses.

The aims of this study were to evaluate dose and volume depending analgesic effects, risks, and side-effects of the maxillary nerve block within the pterygopalatine fossa performed by the EFBI-technique. Further, the effectiveness of the nerve block was tried to assess with pain sensation experiments. 


\section{Materials and methods}

\section{Preliminary experiment}

Ten warmblood horses (six mares and four geldings, 3 to 23 years old) owned by the Clinic for Horses of the University of Veterinary Medicine Hannover, Foundation, without any dental or periodontal diseases were trained to tolerate a mouth gag without sedation. A mechanical stimulus was applied on the palatal gingiva at the level of the second and third maxillary premolar (106/107 and 206/207) by a metallic probe with a diameter of $1.5 \mathrm{~mm}$. The probe was pricked into the gingiva five times over 1 to $3 \mathrm{~mm}$ (Fig. 1). Subsequently, swabs were soaked with cooling spray (Sport Cooling Spray ${ }^{\circledR}$, Henry Schein, Gillingham, UK), and placed on the occlusal surface of the second and third maxillary premolar (106/107 and 206/207) for 15 seconds. Reactions of the horses in response to mechanical and thermal cold stimuli were recorded.

\section{Main experiment}

Animals

Ten warmblood horses (eight mares, one gelding and one stallion, 5 to 23 years old) owned by the Clinic for Horses of the University of Veterinary Medicine Hannover, Foundation, were included in the present study. All animals were free from dental or periodontal diseases.

Study design

The study was designed as a randomised, prospective, blinded, crossover experimental trial with four weeks washout period between the trials. Every horse $(n=10)$ was used for two experiments $(n=20)$. Horses were assigned to receive a maxillary nerve block performed with either $2 \mathrm{ml} / 100 \mathrm{~kg}$ BW lidocaine (group low) or $4 \mathrm{ml} / 100 \mathrm{~kg} \mathrm{BW}$ lidocaine (group high).

Pre-experimental examination and treatment

Horses were placed in stocks and a clinical examination was performed by investigator A. Subsequently the head region was examined, with special focus on the form of the cranium, the masticatory muscles, asymmetry or enlargement, nasal

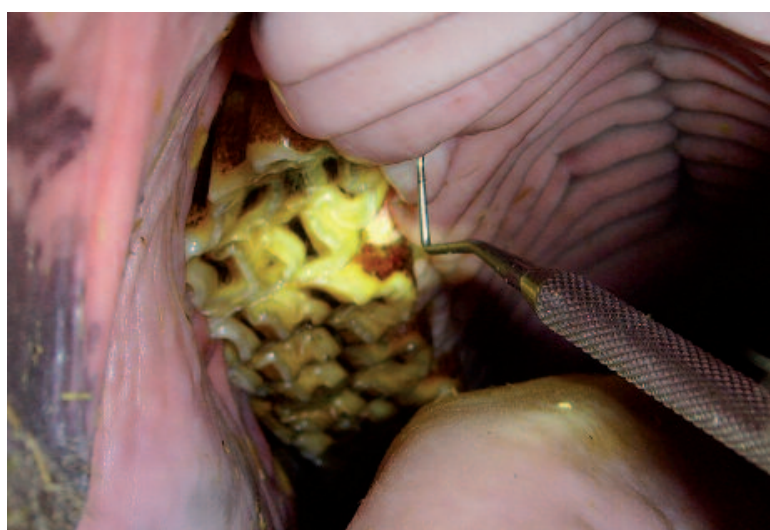

Fig. 1 Mechanical stimulation with a metallic probe on the palatal gingiva on the level of the second premolar (106). I Mechanische Stimulation der palatinalen Gingiva auf Höhe des zweiten prämolaren Backenzahnes (106) mit einer stumpfen Metallsonde secretion or lacrimation, the salivary glands, and the mandibular lymphnodes. Thereafter, horses were sedated intravenously with detomidine $\left(0.02-0.03 \mathrm{mg} / \mathrm{kg}\right.$ Domosedan ${ }^{\circledR}, \mathrm{Pfi}-$ zer, Berlin, Germany) to effect. Heart rate and respiratory rate were recorded during the whole experiment at intervals of five minutes for 35 minutes.

Nerve block

After sedation investigator B performed the maxillary nerve block at a randomly chosen side of the head. The maxillary nerve block was performed in the fossa pterygopalatina according to the EFBl-technique-recommendations by Staszyk et al. (2008). The puncture site was determined $10 \mathrm{~mm}$ ventral to the zygomatic arch at a transversal plane between the middle third and the caudal third of the eyeball (Fig. 2). The puncture site was clipped, washed, and aseptically prepared. Subsequently the skin was desensitized by a subcutaneous injection of $2 \mathrm{ml}$ lidocaine (Licocainhydrochlorid ${ }^{\circledR} 2 \%$, Belapharm, Langförden, Germany). To allow blinding of investigator A, the non-anaesthetized contralateral side of the head was clipped and aseptically prepared as well.

For the nerve block a $0.9 \times 90 \mathrm{~mm}, 20 \mathrm{G}$ spinal needle (Neoject $^{\circledR}$, Dispomed Witt oHG, Gelnhausen, Germany) was inserted at a $90^{\circ}$ angle to the surface of the skin and pushed forward through the masseter muscle $(30$ to $35 \mathrm{~mm}$ ) until the intersection of the inner fascia of the masseter muscle towards the extraperiorbital fat body was noticed due to a change in resistance. After passing the intersection between the masseter muscle and the extraperiorbital fat body the needle was advanced for another $10 \mathrm{~mm}$, followed by aspiration and injecting the anaesthetic.

After performing the maxillary nerve block, the clipped areas were covered with swabs on both sides of the head before attaching the gag. Defense reactions during the performance of the nerve block in terms of a short tremor of the head, weak chewing, or aspirating blood and therefore correcting the placing of the spinal needle were recorded by investigator B. The second experiment in every horse (four weeks after the first

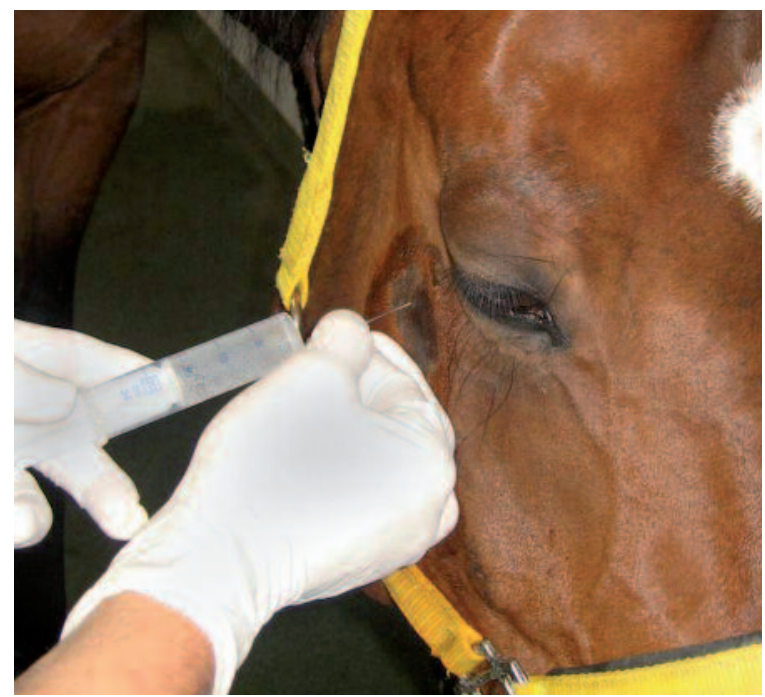

Fig. 2 Performance of the maxillary nerve block (EFBI-technique) with positioning of the needle on the right side of the head. | Anästhesie des N. maxillaris mittels EFBI-Technik auf der rechten Kopfseite des Pferdes 
experiment) was always performed at the contralateral side of the head, using the alternative volume of anaesthetic.

\section{Recording clinical data}

Ten minutes after sedation and before the performance of the nerve block, a Schirmer tear test was conducted on both sides of the head by investigator $A$. This was repeated ten minutes after the performance of the nerve block. Heart rate, respiratory rate, sweating, and a change in the pupil size were recorded every 5 minutes for 35 minutes. Special attention was paid to detect any topical and systemic side effects or complications. Four hours after lidocaine injection and then every 24 hours for at least three days examinations of the eye were performed to detect any abnormalities. The puncture site was checked for swelling or irritation of the skin. In case of any pathological findings the examinations were continued until achieving physiological conditions again.

\section{Testing pain sensation}

Pain sensation was tested on both sides of the head by investigator A. Mechanical and thermal stimulations were performed ten and 25 minutes after the maxillary nerve was blokked, each for a five-minute-interval: A mechanical stimulus was produced on the palatal gingiva in the range of the second and fourth premolar (106/206 and 108/208) with a metallic probe according to the preliminary experiment. A thermal stimulus was set on the occlusal surface of the second and third premolar (106/206 and 107/207) with the help of cooling spray. A small flexible plastic tube (length: $60 \mathrm{~mm}$ ) on the notch of the aerosol enabled a controlled spraying on the occlusal surface for 5 seconds on each tooth (Fig. 3).

The respective stimuli were replicated a few times. Occurrence, type, and amount of specific reactions were recorded. The parameters for defense reactions (headshaking, headbanging, chewing) were assessed by using a scoring system with three categories (no reaction [0], weak reaction [1], strong reaction [2]). The weak reaction related to headshaking and headbanging was defined as excitabilities less than five times per each five-minute-interval, the corresponding strong reaction meant the excitability was shown more than five times per interval. Chewing was considered as weak reaction when the horse showed a slow chewing motion with marginal agitation of the

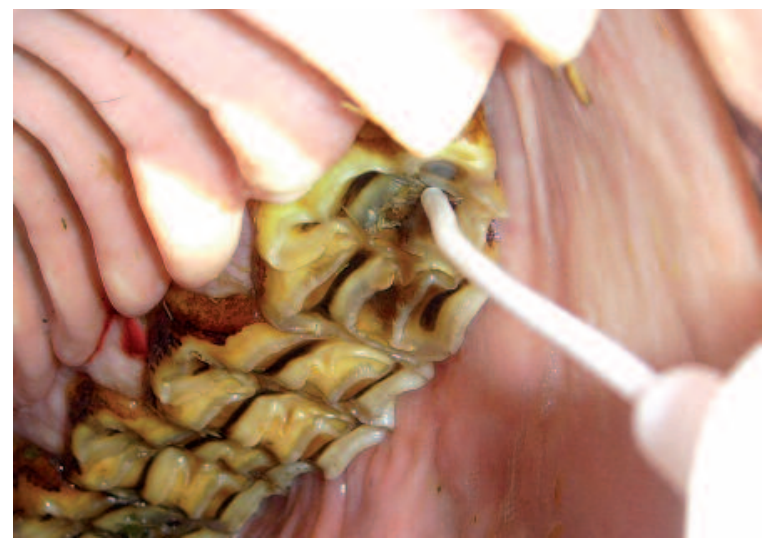

Fig. 3 Thermal stimulation set on the occlusal surface of the second premolar (206) with cooling spray. I Thermische Stimulation der Okklusionsfläche des zweiten Prämolaren (206) mittels Eisspray tongue; according to this, strong reaction meant an articulated chewing motion with heavy defense reactions of the tongue. Behaviors of the horse (stepping forward or stepping back, vocalization, sweating) were assessed by using a scoring system with two categories (no reaction [0], reaction [1]).

\section{Follow up examinations}

The horses were clinically examined four hours after the experiment and then every 24 hours for three days. Special attention was payed to the injection site for any swelling or secondary bleeding. The eyes were monitored for blepharospasm, miosis, or swollen palpebrae. If there were complications due to the anaesthesia, the horses were controlled daily and medicated until complete recovery.

\section{Statistical analysis}

The sum of all scores of defense reactions and behavior of every horse were analyzed for differences between the anaesthetized and the non-anaesthetized side of the head, for different volumes of lidocaine, for different stimuli (thermal, mechanical) and for the data of the Schirmer tear test within an animal using the Wilcoxon-paired test. Differences were considered significant if $p<0.05$. Differences in heart rate and respiratory rate between the measurements with the desensitized and non-desensitized side of the head were assessed using a mixed model (ProcMixed, SAS, version 9.2), corrected for repeated measures within an animal. Differences were considered significant if $p<0.05$.

\section{Results}

Preliminary experiment

Thermal as well as mechanical stimulation resulted in a response in all non-sedated and with a mouth gag equipped horses, independent from the side of stimulation (Fig. 4).

\section{Main experiment}

Maxillary nerve block

The practical application of the maxillary nerve block within the pterygopalatine fossa was well tolerated by all horses in all 20 experiments. The nerve block could be performed with the EFBI-technique and the deep fascia of the masseter muscle was palpable in all 20 experiments. None of the horses showed signs of defense or pain when performing the nerve blokks. In one horse venous blood was aspirated before injection of lidocaine; therefore the spinal needle was repositioned.

Assessment of the analgesic effect

No statistically significant differences for the parameters chewing, headbanging, headshaking, or in behavior (stepping forward or stepping backward, vocalization) were detected during mechanical or thermal stimulation between the anaesthetized and the non-anaesthetized side of the head at both time points. Furthermore, there were no significant differences when comparing both injection volumes. No horse showed 
forward stepping and one horse showed backwards stepping when applying the cooling spray on the non-anaesthetized side of the head at the first time point of sensitivity testing. In one horse applying the mechanical stimulus on the palatal gingiva of the non-anaesthetized side of the head resulted in headshaking (weak reaction [1]) at the first time point of sensitivity testing. In another horse applying the cooling spray on the occlusal surface of the second and third premolar of the non-anaesthetized side of the head resulted in headshaking (weak reaction [1]) at the first time point of sensitivity testing. The results of the parameters "chewing" and "headbanging" were shown in Figure 5.

\section{Clinical examinations}

Two horses showed mild signs of sweating during the experiment (one horse in group low, the other horse in group high). There were no statistically significant changes in heart rate or
Fig. 4 Preliminary experiment: defense reactions of unsedated horses $(n=10)$ during the mechanical and thermal stimuli. | Vorversuch: Abwehrbewegungen der unsedierten Pferde $(n=10)$ während der mechanischen und thermischen Stimulation

\section{Preliminary Experiment: Defense Reactions}

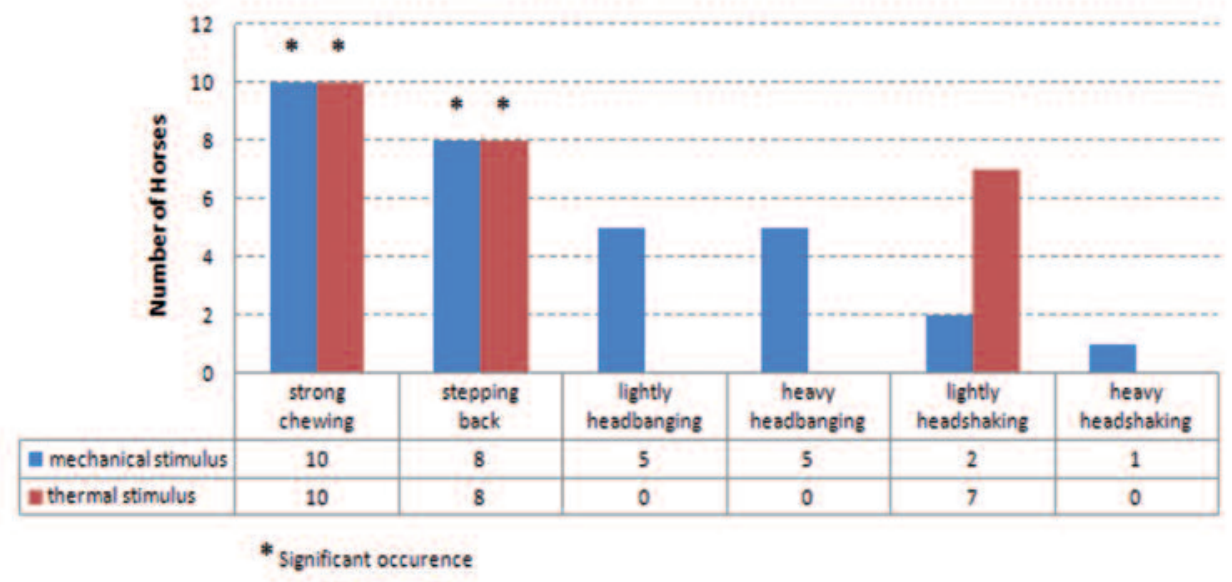

\section{Group low ( $2 \mathrm{ml}$ lidocaine/100kg): CHEWING}

ms anaesthetized side * $=$ ts anaesthetized side *

= $\mathrm{ms}$ unanaesthetized side $\mathrm{in}$ ts unanaesthetized side

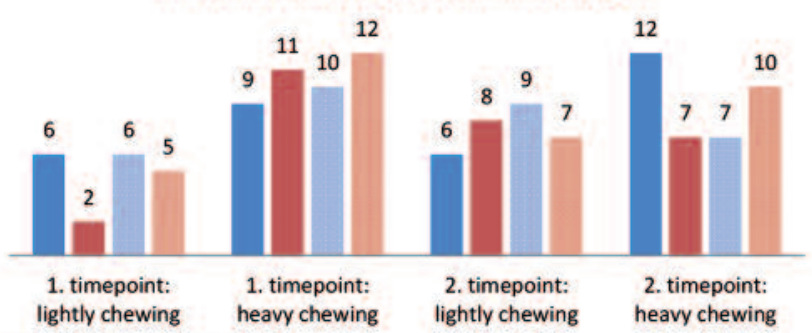

* $\mathrm{ms}=$ mechanical stimulus

$* t s=$ thermal stimulus

\section{Group low (2ml lidocaine/100kg): HEADBANGING}

\begin{abstract}
ms anaesthetized side *
m ts anaesthetized side *

ins $\mathrm{ms}$ unanaesthetized side

ts unanaesthetized side
\end{abstract}

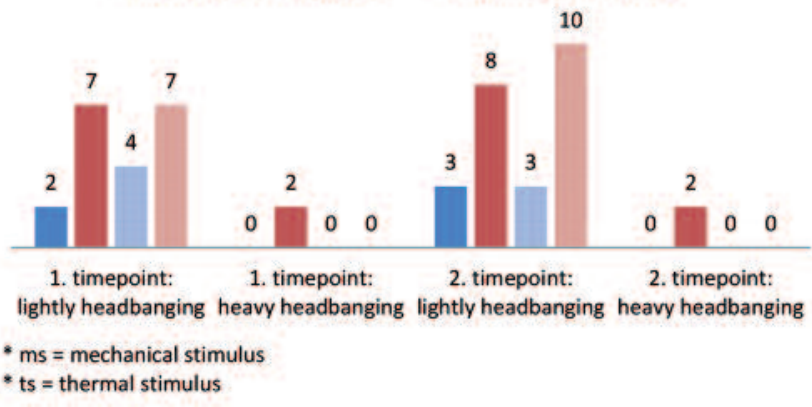

\section{Group high (4ml lidocaine/100kg): CHEWING}

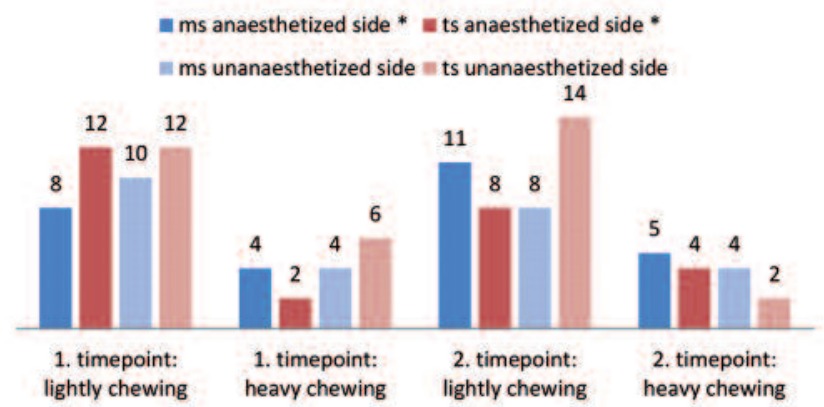

Fig. 5 Main experiment: defense reactions of sedated horses during the mechanical and thermal stimuli (left - group low: $2 \mathrm{ml} / 100 \mathrm{~kg}$ BW lidocaine; right - group high: $4 \mathrm{ml} / 100 \mathrm{~kg}$ BW lidocaine). I Hauptversuch: Abwehrbewegungen der sedierten Pferde während der mechanischen und thermischen Stimulation auf der nicht anästhesierten bzw. anästhesierten Seite des Kopfes (links - Gruppe "low": 2 ml Lidocain/100 kg Körpergewicht $\infty$ rechts - Gruppe "high": 4 ml Lidocain/100 kg Körpergewicht) 
respiratory rate in any horse during the examination period. Furthermore, no alteration of the pupils was noticed during the examinations.

\section{Lacrimation rate}

On the anaesthetized side of the head the lacrimation rate decreased after the nerve block in 12 out of 20 horses (60\%), in 2 horses (10\%) the lacrimation rate was constant, and in 6 horses $(30 \%)$ the lacrimation rate increased, independent of the volume of lidocaine. On the non-anaesthetized side the lacrimation rate decreased in 10 out of 20 horses (50\%), in 4 horses $(20 \%)$ the lacrimation rate was constant, and in 6 horses (30\%) the lacrimation rate increased independent of the volume of lidocaine. However, these data were not statistically significant.

\section{Complications}

Complications were observed in 4 (out of 20) experiments: Three horses showed moderate blepharospasm, miosis, and swollen eye lids on the anaesthetized side (two horses of group low and one horse of group high) 6 to 10 hours after lidocaine injection. Within these horses the lacrimal fluid decreased after the local nerve block on the anesthetized side of the head. Subsequently, these horses developed corneal ulceration followed by uveitis during the first days after injection. They recovered completely after symptomatic treatment with eye ointment locally and NSAIDs systemically within three weeks. One horse (group high) developed a subcutaneous haematoma at puncture area and a superficial ulcer on the cornea on the anaesthetized side of the head. Symptoms completely resolved after local therapy with antibiotic eye ointment for five days.

\section{Discussion}

Standing sedation in horses using $\alpha 2$-agonists has gained popularity as an alternative to general anaesthesia for dental and paranasal procedures because of lower risks for anaesthesia related complications and lower costs. A reliable sedation is essential to guarantee a relaxed handling with the full mouth gag and to ensure a complete and gentle examination of the oral cavity of the horse. Further sedation allows safe performance of regional or local anaesthesia, especially the maxillary nerve block, with reduced risk for complications. The use of regional or local anaesthetic techniques produces superior analgesia and is therefore essential for surgical procedures (Tremaine 2007). Testing the efficacy of a local nerve block before starting surgery would even more help to minimize the risk for defense reactions.

Aim of the preliminary experiment was to evaluate typical responses of non-sedated and non-blocked horses to mechanical and thermal stimulation tests. A reliable test should evoke a response with a high sensitivity. Ten out of ten horses showed strong chewing and eight out of ten horses showed backward stepping as a response to stimulation making these parameters good indicators for nociception. Other typical behavior responses as headbanging or headshaking were only seen in five out of ten horses after mechanical and in no horse after thermal stimulation and are therefore not suitable for evaluating pain responses. The use of behavioral responses to evaluate analgesic effects is further complicated by interindividual different reaction to identical pain stimuli (Livingston 2010).

In addition to high sensitivity a good testing system should have a high specificity. Manipulation of the mouth cavity can cause defense even in sedated horses (Rohr et al. 1986, Alitalo 1986). In the present research project some horses already started with adverse behavior (chewing, headbanging) after opening the gag and entering one hand or the equipment into the oral cavity. Therefore it is likely that some responses were evoked only by the "awareness" of nociceptive stimulation. One opportunity to objectify the response to the used pain sensation tests could be by blindfolding the horse avoiding any defense reactions just to the implementation of the hand, the probe or the cooling spray into the oral cavity. In addition, ear plugs could help to reduce the sensitivity of the horses to the sound of the cooling spray (Gough 1997).

One aim of the main experiment was to prove the practicability of different pain sensation tests for the verification of efficacy of the maxillary block. Although the amount and strength of defense reactions were reduced in horses of the main experiment compared to the horses of the pretrial, there was no difference between responses after stimulation of the anaesthetized or the non-anaesthetized side of the head using either the mechanical or the thermal stimulus. One reason might be the impact of the analgesic properties of the detomidine used in these horses (Kamerling et al. 1988). Beside its analgesic properties detomidine produces a dose dependent deep sedation (Clarke and Taylor 1985), which might also lead to a lack of antinociception. Therefore it was not possible to distinguish whether the lack of defense reaction was caused by local anaesthesia or sedation. Sedation alone is probably as efficient as sedation combined with local anaesthesia to reduce the pain sensation responses of the occlusal surface of the teeth and the surrounding gingiva in the horse, but is not likely to be efficient enough for surgical interventions. Probably further studies using an electric pulp tester (Certosimo and Archer 1996) instead of cooling spray will investigate and predict the efficacy of local dental anaesthesia. In the present study defense reactions of the horse concerning heavy pain during dental surgery, e.g. cheek tooth extraction, was not examined, thus no conclusion is possible.

Another aim was to evaluate the clinical performance of the EFBl-technique and the impact of volume on the effectiveness of the maxillary nerve block by using two different volumes of local anaesthetic. It is proven, that the maxillary nerve block desensitizes the ipsilateral paranasal sinuses, nasal cavity, maxillary and premaxillary teeth and associated alveoli and gingiva (Fletcher 2004, Moyer et al. 2011). Our study demonstrated the ability of the clinical performance of the maxillary nerve block within the pterygopalatine fossa. The anaesthesia could be performed with the EFBI-technique in all of the 20 experiments and should guarantee a complete and reliable analgesia of the maxillary cheek teeth arcade. Brunetto et al. (2008) evaluated the minimal dosage of a local anaesthetic for the infiltration of the maxillary nerve in dogs. In this study a volume of $1.2 \mathrm{ml}$ of lidocaine (with epinephrine) provided a faster onset, a higher success rate, and a longer duration of anaesthesia when compared to volumes 
less than $1.0 \mathrm{ml}$ (Brunetto et al. 2008). In horses recommended volumes of local anaesthetic for maxillary nerve block are 10 to $30 \mathrm{ml}$ (Stephenson 2004, Dixon 2006, Tremaine 2007, Moyer et al. 201 1). In contrast to these recommendations a dissection study found these volumes to be excessive for complete nerve coverage (Bardell et al. 2010). In addition Staszyk et al. (2008) showed that an injection volume of $10 \mathrm{ml}$ into the extraperiorbital fat body was as sufficient for achieving complete diffusion around the targeted maxillary nerve as a volume of $20 \mathrm{ml}$ in skulls of a horse with $500 \mathrm{~kg}$ BW. O'Neill et al. (2014) did not use volumes of more than $10 \mathrm{ml}$ in clinical cases as the needle is positioned adjacent to the nerve using ultrasound guidance. According their results they anticipated that smaller volumes might be also sufficient. The present study demonstrated that the lower volume of $2 \mathrm{ml} / 100 \mathrm{~kg}$ BW lidocaine applied for the local maxillary nerve block in the pterygopalatine fossa resulted in no significant increase of the defense reactions or worsening in behavior of the horse. In this regard, the expected deviant effects on the anaesthetized and the non-anaesthetized side of the head were damped down or not existent. Potentially, this fact could be again influenced or ascribed to the sedation of the horse or the insufficient pain sensation tests. According to Lowder (2012) complications from equine dental nerve blokks could be minimized if the practitioner might consider using the lowest effective drug volume.

Low- and mid-graded complications after the maxillary nerve block appeared in group low and high. The temporary mild sweating of two horses during the trial might be a side-effect of the sedation with detomidine (Gasthuys et al. 1987) and not a consequence of the maxillary nerve block. Horses of both groups showed long-term consequences as blepharospasm, miosis, swollen upper and lower palpebrae, uveitis, a superficial ulcer or a small subcutaneous hematoma. Even the lower volume of $2 \mathrm{ml} / 100 \mathrm{~kg}$ BW lidocaine probably evokes retrobulbar pressure and may induce irritations for the horse. Possibly rubbing of the relevant side of the head could be one reason for the superficial ulcer seen in this study. Another reason for discomfort and therefore rubbing of the head could be a decrease of the lacrimal fluid caused by the maxillary nerve. It has been shown that interruption of parasympathetic innervation to the lacrimal gland leads to rapid reduction in tear flow (Nguyen et al. 2006), because the tear production is stimulated by parasympathetic nerve fibers. Blokking the maxillary nerve in the pterygopalatine fossa inevitably also blocks the parasympathetic pterygopalatine ganglia which are located medial to the maxillary nerve, and consequently lacrimation rate might be reduced. This hypothesis could be confirmed in our study using the Schirmer tear test before and after local nerve block. Although not being significant, more horses showed a decreased lacrimal fluid after the nerve block. Deficiencies in aqueous tear production (e.g. keratoconjunctivitis sicca or "dry eye") have been recognized as a frequent cause of corneal and conjunctival lesions in both humans and animals (Pflugfelder 1998, Gelatt 2007). Although there was no significant difference between the lacrimal fluid on both sides of the head before and after the local nerve block in our study, in three of four cases with a long-term consequence on the anesthetized side of the head the lacrimal fluid was decreased after the local nerve block. Staszyk et al. (2008) reported that the EFBI-technique reduces the risk of puncturing the deep facial vein, the infraorbital artery, and the descending palatine artery, since the needle is not inserted close to the palatine bone and consequently stays away from these blood vessels. Considering these results, the EFBI-technique could minimize complications like retrobulbar hematoma, edema, and neuritis which have been observed after the palatine bone injection technique (Fletcher 2004, Tremaine 2010). Also these complications are not completely inevitable with the EFBI-technique, the risk becomes minimized. In the present study none of the horses showed signs of hematoma, e.g. exophthalmos, or signs of an ascending infection. Regarding the complex anatomy and the direct proximity to the central nervous system, it is of outstanding importance to guarantee an absolute steril application technique during the performance of the local nerve block.

\section{Conclusion}

The maxillary nerve block performed with the EFBI-technique is a feasible clinical technique. Influenced by sedation, a general appraisement for sufficient analgesia of the maxillary cheek teeth with the performed tests (mechanical and thermal stimulation) could not be attained. The statistical analysis of the defense reactions showed no difference between the high and low volume of lidocaine and the non-desensitized side. A precise knowledge of the anatomic situation, a sterile application technique, and aspiration prior injecting the local agent are essential. Including these facts, local anaesthesia of the maxillary cheek teeth arcade with the EFBI-technique offers the possibility for advanced dental surgery with the horse standing and sedated. Risks are not completely avoidable but maintainable in view of the advantages. Using ultrasonographic landmarks of the pterygopalatine fossa, local anaesthetic can be deposited around the maxillary nerve without the inadvertent penetration of adjacent vital structures (O'Neill 2014). Clinical investigations in the context of maxillary cheek tooth extractions would be beneficial to evaluate our results. These further investigations should include preventive treatment of eye ointment and monitor possible complications occurring with the high or low volume of lidocaine.

\section{Animal Welfare Statement}

The study was approved by the animal welfare officer of the University of Veterinary Medicine Hannover, Foundation, and the Ethical Committee of the Lower Saxony State Office for Consumer Protection and Food Safety (No. 09/1756).

\section{Conflict of Interest Statement}

The authors exclude any conflict of interest.

\section{References}

Ahlquist M. L., Edwall L. G., Franzen O. G., Haegerstam G. A. (1984) Perception of pulpal pain as a function of intradental nerve activity. Pain 19, 353-366

Alitalo I. O. (1986) Clinical experience with Domosedan ${ }^{\circledR}$ in horses and cattle. Acta Vet. Scand. 82, 193-196

Bardell D., Iff I., Mosing M. (2010) A cadaver study comparing two approaches to perform a maxillary nerve block in the horse. Equine Vet. J. 42, 721-725 
Brunetto P. C., Ranali J., Ambrosano G. M. B., de Oliveira P. C., Groppo F. C., Meechan J. G., Volpato M. C. (2008) Anesthetic efficacy of 3 volumes of lidocaine with epinephrine in maxillary infiltration anesthesia. Anesth. Prog. 55, 29-34

Certosimo A. J., Archer R. D. (1996) A clinical evaluation of the electric pulp tester as an indicator of local anaesthesia. Oper. Dent. $21,25-30$

Clarke K. W., Taylor P. M. (1985) Detomidine in horses. Vet. Rec. $117,674-675$

Costa C. G., Tortamano I. P., Rocha R. G.. Francischone C. E., Tortamano N. (2005) Onset and duration periods of articaine and lidocaine on maxillary infiltration. Quintessence Int. 36, 197-201

Dixon P. M. (2006) Apical infections of cheek teeth and their oral extraction. In: Proceedings of the American Association of Equine Practitioners Focus Meeting, Indianapolis, Indiana, USA

Evans G., Nusstein J., Drum M., Resder A., Beck M. (2008) A prospective, randomized, double-blind comparison of articaine and lidocaine for maxillary infiltrations. J. Endod. 34, 389-393

Fletcher B. W. (2004) How to perform effective equine dental nerve blocks. Proc Am Assoc Equine Pract, Denver, USA, 233-239

Funakoshi M., Zotterman Y. (1963) A study in the excitation of dental pulp nerve fibres. In: Sensory Mechanisms in Dentine. D. J. Anderson (Hrsg), Macmillan, New York, USA, 60-70

Gasthuys F., Terpstra P., van den Hende C., De Moor A. (1987) Hyperglycaemia and diuresis during sedation with detomidine in the horse. J. Vet. Med. A., 641-648

Gelatt K. N. (2007) Ophtalmic Examinations and Diagnostics. In: Veterinary Ophtalmology. 4th Ed. K.N. Gelatt (Hrsg), Blackwell Publisher, Oxford, UK, 462-463

Gough M. R. (1997) Nursing Notes, Clipping horses. Equine Vet. Educ. 9, 161-165

Gross M. E., Pope E. R., Jarboe J. M., O'Brien D. P, Dodam J. R., Polkow-Haight J. (2000) Regional anaesthesia of the infraorbital and inferior alveolar nerves during noninvasive tooth pulp stimulation in halothane-anesthetized cats. Am. J. Vet. Res. 61, 1245-1247

Hensel H., Mann G. (1956) Temperaturschmerz und Wärmeleitung im menschlichen Zahn. Stoma 9, 76-85

Kamerling S. G., Cravens W. M., Bagwell C. A. (1988) Objective assessment of detomidine-induced analgesia and sedation in the horse. Eur. J. Pharmacol. 151, 1-8

Livingston A. (2010) Pain and Analgesia in Domestic Animals. In: Comparative and Veterinary Pharmacology. F. Cunningham, J. Elliott, P Lees (Hrsg). Springer, Berlin, Heidelberg, Germany, 159-189

Lowder M. Q. (2012) Equine dental nerve blocks. Equine Vet. Educ. 24, 124-125

Moyer W., Schumacher J., Schumacher J. (2011) Regional Anesthesia: Nerve blocks of the head. In: Equine Joint Injection and Regional Anesthesia. 4. Aufl., W. Moyer, J. Schumacher, J. Schumacher (Hrsg) Academic Veterinary, 120-121

Nguyen D. H., Vadlamudi V., Toshida H., Bevermann R. W. (2006) Loss of parasympathetic innervation leads to sustained expression of pro-inflammatory genes in the rat lacrimal gland. Auton. Neurosci. 124, 81-89

Naylor M. N. (1964) Studies on sensation to cold stimulation in human teeth. Brit. Dent. J. 117, 482-486

Nottrott K., Schramme M. C., Lepage O. (2014) Efficacy of ultrasound-guided local analgesia of the maxillary nerve within the pterygopalatine fossa in the horse. Proc. ECVS Annual Scientific Meeting, Copenhagen, Denmark

O'Neill H. D., Garcia-Pereira F. L., Mohankumar P. S. (2014) Ultrasound-guided injection of the maxillary nerve in the horse. Equine Vet. J. 46, 180-184

Pflugfelder S. C. (1998) Advances in the diagnosis and management of keratoconjunctivitis sicca. Curr. Opin. Ophthalmol. 9; 50-53

Rohr W., Schatzmann U., Wyss H., Tschudi P. (1986) Detomidin $\left(\right.$ Domosedan ${ }^{\circledR}$ ). Ein neues Sedativum und Analgetikum für Pferde. Pferdeheilkunde 2, 207-210

Staszyk C., Bienert A., Bäumer W., Feige K., Gasse H. (2008) Simulation of local anaesthetic nerve block of the infraorbital nerve within the pterygopalatine fossa: Anatomical landmarks defined by computed tomography. Res. Vet. Sci. 85, 399-406
Stephenson R. (2004) Oral extraction of equine cheek teeth. UK Vet., $11-17$

Tremaine W. H. (2007) Zahnentfernung. In: Zahnheilkunde in der Pferdepraxis. G.J. Baker, J. Easley (Hrsg). Elsevier Urban and Fischer, München, Deutschland, 287

Tremaine H. (2010) Regional analgesia of the horse's head. Proceedings of the 49th BEVA Congress, Birmingham, UK, 174

Trowbridge H. O., Franks M., Korostoff E., Emling R. (1980) Sensory response to thermal stimulation in human teeth. J. Endod. 6, 405-412

Vlaminck L., Steenhaut M. (2001) Extractie van de maaltanden bij het paard. Vlaams Diergeneeskundig Tijdschrift 70, 337-343

Vlaminck L., Verhaert L., Steenhaut M., Gasthuys F. (2007) Tooth extraction techniques in horses, pet animals and man. Vlaams Diergeneeskundig Tijdschrift 76, 249-261

Wagers P. W., Smith C. M. (1960) Responses in dental nerves of dogs to tooth stimulation and the effects of systematically administered procaine, lidocaine and morphine. J. Pharmacol. Exp. Ther. 130, 89-105

Yamada M., Suzuta K., Higuchi H. (1968) Sensitivity of the tooth to thermal stimulation. Jpn. J. Physol. 18, 310-325

Erweiterte Zusammenfassung

\section{Anästhesie des N. maxillaris in der Fossa pterygopalati- na mit unterschiedlichen Injektionsvolumina beim Pferd: Durchführbarkeit, Wirkung und Risiken}

Die Anästhesie des N. maxillaris in der Fossa pterygopalatina zählt in der Backenzahn- und Nasennebenhöhlenchirurgie des Pferdes zu den gängigen perineuralen Anästhesien. Operationen am stehenden, sedierten Pferd können dadurch in größerer Zahl, sicherer und tierschutzgerechter durchgeführt werden. In der Literatur sind diverse Risiken der Anästhesie beschrieben, die mit der Technik an sich, dem Injektionsvolumen, aber auch mit den anatomischen Besonderheiten dieser Region zusammenhängen. Eine Minimierung der Risiken wurde durch die Extraperiorbitale-Fettkörper-Anästhesie (EFBITechnik) von Staszyk et al. (2008) erreicht. In bisherigen, meist experimentellen Studien wurden unterschiedliche Injektionsvolumina angewendet, deren ausreichende klinische Wirkung und potentielle Risiken aber nicht näher untersucht. Das Ziel der vorliegenden prospektiven, randomisierten und verblindeten klinischen Arbeit war es zum einen, mögliche Risiken und Nebenwirkungen der Anästhesie des N. maxillaris in der Fossa pterygopalatina unter Verwendung von zwei unterschiedlichen Mengen an Lokalanästhetikum zu determinieren. Zum anderen sollten mögliche Methoden evaluiert werden, mit denen in der täglichen Praxis eine adäquate Schmerzausschaltung an den Zähnen und der umgebenden Gingiva beurteilt werden kann.

In einem Vorversuch wurden zehn unsedierte Pferde an das Einbringen eines Maulgatters gewöhnt. Im Anschluss wurden bei geöffnetem Maul wiederholt thermische und mechanische Reize an der Gingiva im Oberkiefer und den Okklusionsflächen der ersten beiden Oberkieferbackenzähne gesetzt. Auf beide Stimuli reagierten alle Pferde reproduzierbar mit typischen Abwehrbewegungen wie starkem Kaven und Zurücktreten.

In den Hauptversuch wurden zehn klinisch gesunde Pferde der Stiftung Tierärztliche Hochschule Hannover inkludiert. Die Tiere wiesen ein unterschiedliches Alter und Geschlecht auf und waren frei von dentalen oder parodontalen Erkrankungen. Jedes Pferd wurde im Rahmen des randomisierten Cross-Over-Designs der Studie insgesamt zweimal an unter- 
schiedlichen Tagen behandelt und untersucht. Die Probanden wurden nach einer klinischen Allgemeinuntersuchung und einer speziellen Untersuchung des Kopfes mit 0,02-0,03 $\mathrm{mg} / \mathrm{kg}$ Detomidin intravenös sediert. Die Anästhesie des N. maxillaris wurde mit der EFBI-Technik jeweils nur auf einer Kopfseite vorgenommen. Die Pferde wurden hierfür im Vorfeld in zwei Gruppen eingeteilt und erhielten entweder $2 \mathrm{ml} / 100 \mathrm{~kg}$ Körpergewicht Lidocain (Gruppe low) oder $4 \mathrm{ml} / 100 \mathrm{~kg}$ Körpergewicht Lidocain (Gruppe high). Abwehrreaktionen der Pferde und Nebenwirkungen während bzw. nach der Anästhesie wurden dokumentiert. Zur Messung des Tränenflusses wurde zehn Minuten vor und zehn Minuten nach der Lokalanästhesie ein Schirmer-Tränentest vergleichend an beiden Augen durchgeführt. Die Schmerzausschaltung durch die Anästhesie des N. maxillaris an den Zähnen und der umliegenden Gingiva wurde jeweils zehn und 25 Minuten nach erfolgter Lokalanästhesie durch länger anhaltende mechanische und thermische Stimuli überprüft. Diese Untersuchungen wurden ebenfalls immer vergleichend auf der anästhesierten und nicht anästhesierten Kopfseite vorgenommen, wobei der Untersucher verblindet war. Kardiorespiratorische Parameter (Herzfrequenz, Atemfrequenz), Schwitzen und Reaktionen der Pupillen wurden vor der Sedierung und Anästhesie des N. maxillaris, sowie im Anschluss alle fünf Minuten über einen Zeitraum von 35 Minuten nach der Anästhesie erfasst. Weitere Untersuchungen des Allgemeinbefindens der Pferde und speziell des Kopfes wurden an drei auf den Versuch folgenden Tagen vorgenommen, um von der Norm abweichende Befunde zu dokumentieren.

In der vorliegenden Studie wurde die Lokalanästhesie des N. maxillaris von den Probanden in allen 20 Versuchen gut toleriert. Keines der sedierten Pferde zeigte während der Anästhesie Abwehrbewegungen, die die Durchführung der Injektion in irgendeiner Weise negativ beeinträchtig hätten. Am sedierten Pferd konnte die Schmerzausschaltung an den Zähnen und der umgebenden Gingiva anhand der durchgeführten Tests mittels mechanischer und thermischer Stimulation nicht ausreichend bewertet werden. Die vergleichende Beurteilung der Abwehrreaktionen beider Kopfseiten (anästhesiert und nicht anästhesiert) zeigte keinen statistisch signifikanten Unterschied. Des Weiteren unterschieden sich die Abwehrbe- wegungen der Pferde mit großer Menge Lidocain (Gruppe high) statistisch nicht signifikant von denen, die die geringere Menge Lidocain erhalten hatten (Gruppe low). Die gemessene Tränenflussrate vor und nach der Lokalanästhesie wies an keinem der Augen statistisch signifikante Unterschiede auf. Es war jedoch nach der Lokalanästhesie die Tendenz einer Verringerung der Tränenflüssigkeits-Produktion zu erkennen. In 16 von 20 Fällen wurden nach der Anästhesie keine Komplikationen oder Nebenwirkungen beobachtet. Dagegen zeigten vier Pferde entweder Blepharospasmus, Miosis, geschwollene Lider, einen oberflächlichen Hornhaut-Ulkus oder Uveitis. Die Symptome verschwanden bei allen Pferden nach symptomatischer Behandlung mit Augensalben (lokal) und nichtsteroidalen Antiphlogistika (systemisch) vollständig.

Obgleich die Fossa pterygopalatina empfindliche anatomische Strukturen beherbergt, erscheint die EFBI-Technik als sichere und praktikable Methode für die Anästhesie des N. maxillaris. Genave anatomische Kenntnisse, eine sterile Vorgehensweise und die Aspiration vor der Injektion des Lokalanästhetikums sind essentiell zur Vermeidung von Komplikationen. Die unterschiedlichen Volumina vom Lidocain schienen keinen Unterschied im Abwehrverhalten der Pferde zu machen. Um zu verifizieren inwieweit dies durch die Sedierung beeinflusst wurde, müssten weiterführende klinische Untersuchungen mit höherem Schmerzlevel, wie z. B. einer Backenzahnextraktion, durchgeführt werden. Die mangelnde Sensitivität der Testmethoden und die Sedierung der Pferde könnten möglicherweise einen signifikanten Unterschied zwischen der Gruppe mit großem und der Gruppe mit geringerem Volumen des Lokalanästhetikums verhindert haben. Die angewandten mechanischen und thermischen Tests zur Überprüfung der Schmerzausschaltung erwiesen sich als nicht geeignet für die tägliche Praxis, da die Pferde zur Anästhesie des N. maxillaris immer sediert werden müssen. Um negativen Folgen am Auge vorzubeugen, die häufiger in der Gruppe mit dem größeren Injektionsvolumen vorkamen, empfiehlt es sich nach der Anästhesie des N. maxillaris pflegende Augensalben zu applizieren, um die Hornhaut feucht zu halten.

Schlüsselwörter: Lokalanästhesie / Analgesie / Pferdezahnheilkunde / Anästhesie / N. maxillaris / Tränenfluss 